\title{
APOTHEKE
}

ESTUDIO DE

P I N T URA

\section{Sobre desenho, memória e aprendizagem: uma abordagem neurocientífica visando a educação inclusiva ${ }^{1}$}

\author{
Maria Lúcia Batezat Duarte (UDESC)
}

\begin{abstract}
RESUMO
Este é um ensaio sobre a memória e o seu lugar na aprendizagem humana. Os fundamentos teóricos são organizados a partir de autores atuais, médicos e psicólogos que trabalham no vasto campo da neurociência. Como objeto de pesquisa e reflexão são apresentados desenhos infantis, os esquemas gráficos que esta produção proporciona, e o modo de confecção dos pictogramas que Piekas e eu (2013) sugerimos para o ensino de crianças com necessidades especiais de aprendizagem.
\end{abstract}

PALAVRAS-CHAVE: aprendizagem, memória, desenho, desenho infantil, educação inclusiva

\section{ABSTRACT}

This is an essay on memory and its place in human learning. The theoretical foundations are organized from current authors, doctors and psychologists working in the vast field of neuroscience. Children's drawings are presented as an object of research and reflection, as well as the graphic schemes that this production provides and the way of making the pictograms that Piekas and I (2013) suggest for the teaching of children with special learning needs.

KEYWORDS: learning, memory, drawings, children's drawings, inclusive education

O canadense M.G. era caçador e desenhista quando sofreu um acidente. Perdeu uma pequena parte do seu cérebro. No processo de recuperação a equipe médica percebeu que M.G. não era mais capaz de realizar os desenhos de observação visual de objetos pelos quais se destacava em sua pequena comunidade. A perda cerebral estava de algum modo impedindo a conexão correta entre o objeto que seu olho via e efetivação de uma correspondência motora suficientemente adequada ao traçado do desenho. Ele foi diagnosticado com apraxia visual (Guerín et al. 1999). Mas, para surpresa da equipe, M.G. foi capaz de desenhar com resultados idênticos aqueles desenhos que tinha por hábito repetir antes do acidente. Eles denominaram esses desenhos "routine drawings" (desenhos de rotina), indicando a dissociação entre o processo cerebral de desenhar "de memória" e o

${ }^{1}$ Parte deste texto foi publicada em: ALMEIDA, A. A e MENDES, E. G. orgs. Educação especial e seus diferentes recortes. Marília: ABPEE, 2016, p. 293-310, com o título: Desenho Infantil e inclusão: a neurociência e os fundamentos teóricos do Vocabulário Pictográfico. 
processo de desenhar observando visualmente um novo objeto. Isto é, verificaram a possibilidade de execução de "desenhos de rotina" sem que as vias cerebrais da visualidade sejam requisitadas, mas apenas a memória associativa, que reconhece o objeto, e a memória procedimental ${ }^{2}$ que armazena a imagem motora necessária ao ato de desenhar.

\begin{abstract}
"Nós concordamos que alguns desenhistas podem reter um desenho de memória apurado mesmo com um déficit de imageria visual. Um desenhista competente com um déficit de imageria visual pode reproduzir alguns objetos de memória apoiado na ativação, pela memória associativa, de operações motoras automáticas memorizadas (...) Um trajeto da memória associativa para a memória procedimental poderia explicar sua habilidade para desenhar alguns objetos, muito familiares e frequentemente reproduzidos, apesar de seu déficit de imageria visual." (Guérin et all., 1999, p. 470)
\end{abstract}

Penso que é possível, em alguns casos, relacionar este fato clínico com o próprio exercício das Artes Visuais. A história do ofício do desenho é plena de repetições e memorizações. Para sua obra principal, Guernica, Picasso realizou mais de dois mil desenhos estudando, repetindo (e apreendendo/memorizando) cada elemento que usaria na composição visual posteriormente consagrada.

Neste ensaio o primeiro ponto considerado é a relação entre memória e aprendizagem a partir da abordagem neurocientífica. o intuito é refletir sobre os diferentes tipos de memória e as várias modalidades perceptivas que atuam na apreensão do mundo e na aprendizagem. No segundo tópico são evidenciados aspectos do desenvolvimento infantil e o papel do desenho (da imagem visual) no estabelecimento de relações concretas e classificatórias entre objetos e seus nomes. Na terceira e última parte a abordagem adotada no "Vocabulário Pictográfico" (DUARTE e PIEKAS, 2013), os procedimentos de elaboração e ensino dessas imagens visuais, são apresentados e discutidos. Pretendo assim, explicitar o valor que atribuo ao ato de desenhar nos processos de aprendizagem ressaltando o entrelaçamento que ele propicia entre a imagem visual simplificada e plana do objeto e a palavra que o nomeia.

\footnotetext{
2 Memória procedimental são representações de "programas de ação" armazenadas solidamente no cérebro. Jeannerod a exemplifica com os gestos cotidianos que não são conscientes e que uma vez aprendidos não precisamos mais reaprendê-los como andar de bicicleta ou fazer tricô. Ver para isso, Guérin et all, 1999 e Jeannerod, 2005.
}

$$
=73=
$$




\section{Sobre aprendizagem e (neuro) ciência}

Antes do final do século XX neurocientistas de todo o mundo já se ocupavam em divulgar, em linguagem acessível aos leigos, as incríveis descobertas sobre o funcionamento do nosso cérebro que as novas tecnologias de imagem estavam permitindo. Entre esses cientistas Armando Rocha, no Brasil, evidenciava uma clara preocupação educacional. Sua palestra na $23^{a}$ Reunião Anual da Associação Nacional de Pesquisa e Pós-Graduação em Educação (ANPEd) em 1999, fez com que eu me encorajasse a ler o seu livro e inúmeros outros, até hoje, sobre esse tema fascinante. ${ }^{3}$

Qual o interesse que as pesquisas sobre o cérebro podem e devem provocar nos educadores? Qual a relação entre essas pesquisas e a educação? Imensas, uma vez que aprender requer a obtenção de percepções e a produção de memorizações processadas na "caixa preta" do nosso cérebro.

A primeira acepção do verbo "aprender" é pegar, pinçar. Mas, nos processos educacionais de ensino-aprendizagem, não basta "pegar", é necessário, também, guardar, armazenar, memorizar. o modo como memorizamos e, portanto, ao modo como aprendemos é uma questão que a neurociência é cada vez mais capaz de responder.

Podemos dizer que o desenvolvimento humano, seja do ponto de vista ontogenético (de cada ser) ou filogenético (de todos os seres humanos que existem e já existiram sobre a Terra), depende da aprendizagem realizada durante a vida ou ao longo desta ou daquela civilização. Uma das questões que a neurociência vem conseguindo comprovar é que aprendemos no percurso de toda a nossa vida e não apenas durante a infância e a adolescência quando o nosso corpo ainda está em crescimento e desenvolvimento. Um corpo adulto e já completamente desenvolvido do ponto de vista físico, externo, pode envolver um cérebro pleno de novas descobertas e aprendizagens." Esclarece Doidge: "Quando aprendemos uma coisa nova, os neurônios disparam juntos e se ligam entre si, e ocorre um processo químico neuronal chamado 'potencialização a longo prazo', que fortalece as conexões entre os neurônios" (DOIDGE, 2011, p.131). Pode-se dizer, também, que conexões fortalecidas indicam o grau de memorização, um dos fatores que qualifica a aprendizagem.

\footnotetext{
3 Destaco ainda Antonio Damásio $(2000,2004,2011)$ nos Estados Unidos, a equipe de Olivier Houdé na França (2004, 2005) e, mais recentemente Alberto Oliverio ( 2013) na Itália, bem como os cientistas brasileiros Roberto Lent (2005) e Miguel Nicolelis (2011).
}

${ }^{4}$ Ver para isso, por exemplo, Bideaud, Houdé e Pedinielli, (2004) ou Doidge (2011).

$$
=74=
$$

ISSN: 2447-1267 Santa Catarina, v.5, n.1, ano 3, março de 2017. 
Usualmente os neurocientistas (Rocha, 1999; Lent, 2005; Oliverio, 2013) apresentam os processos de memória a partir de uma primeira grande subdivisão: memória implícita e memória explícita. É denominada memória implícita aquela que se manifesta por meio de ações que ocorrem sem que o sujeito atuante tenha plena consciência ou sinta-se "raciocinando" a cada passo da ação que empreende. É a memória implícita (ou subentendida) que nos permite, por exemplo, após um período de treinamento, passar a dirigir um automóvel sem que seja necessário ficar atentamente repassando na mente cada etapa da sequencia de ações a serem executadas, como fazíamos no processo inicial de aprendizagem. Um outro nome para designar esse tipo de memória é "memória procedimental", ou "de procedimento". Ela está altamente vinculada à motricidade ${ }^{5}$ e às atuações do nosso corpo, seja na aquisição ou manutenção de hábitos, como escovar os dentes ou dirigir um automóvel (procedimentos de repetição), seja nos automatismos mais básicos de proteção, como erguer braços e mãos para evitar um golpe na cabeça ou correr de algo que nos ameaça (procedimentos reflexos).

Diferente da memória implícita, a memória explícita demanda evocação e/ou consciência. O outro nome utilizado para indicar esse tipo de memória é "memória declarativa". Os dois termos, declarado ou explícito, convergem quando eles põem em evidência uma clara presença, na mente, de um dado ${ }^{6}$ obtido com antecedência. Oliverio (2013, p.111 e ss.) relaciona esse tipo de memória a uma aquisição (um dado) obtida por meio de experiências pessoais, as vezes sem que o sujeito da memória tivesse a intenção de obtê-la, ou por meio de estudos programados, quando o sujeito teve um intenção evidente de obter este ou aquele dado (conhecimento). A memória explícita pode receber algumas subdivisões segundo a sua abrangência (autobiográfica e semântica) e a sua duração (de curto prazo, de trabalho, e de longo prazo). A memória explícita autobiográfica responde a uma evocação de fatos (dados/significados) atrelados à história pessoal e particular de um sujeito. A memória explícita semântica responde a evocação de um significado aprendido na cultura, isto é, um significado atribuído a fatos (dados mentais)

\footnotetext{
${ }^{5}$ Oliverio (2013, p.111 e ss.) localiza esse tipo de memória especialmente nos glângios basais e no cerebelo.

"A palavra "dado" será usada ao longo deste texto para indicar uma ação, um evento, qualquer tipo de aquisição mental que implique permanência e memória.
}

$$
=75=
$$


que é válido e similar para todos os sujeitos de uma mesma sociedade ou comunidade linguística. A memória explícita semântica também pode ser denominada episódica especialmente quando um determinado dado mental e seu significado estiverem circunscritos a um determinado espaço geográfico e/ou a uma determinada época (episódio). ' As memórias explícitas podem, segundo a necessidade dos sujeitos, e as demandas da sua existência, ter uma longa duração ou uma curta duração. Assim, são adjetivadas com os termos "de curto prazo" e "de trabalho" quando após um período de utilidade aquele grupo de dados deixa de ser necessário (nome e sobrenome do nosso chefe, por exemplo, que cai em desuso se deixamos aquele emprego ou há uma troca de cargos e pessoal ) e "de longo prazo" quando é requerida constantemente ao longo de nossa vida como, por exemplo, a conjugação dos verbos na língua falada e escrita que utilizamos em nossa comunicação diária.

Antonio Damásio (2011) defende outra subdivisão para os processos de memória. Ele qualifica a memória como "única" e "não única". Na memória "não única", Damásio inclui, com ênfase, a memória semântica, aquela que mais acima se classificava como uma subdivisão da "memoria explícita". De fato, Damásio parece usar como critério desta subdivisão dois fatores: a) a dinâmica cerebral, isto é, quais as vias neurais, quais os circuitos ou mapas que são ativados durante essa ou aquela rememoração/evocação, relacionados aos processos denominados pelos neurocientistas "O que?" e "Onde?"; e, b) a complexidade, isto é, o trabalho cerebral exigido para essa ou aquela evocação.

Os circuitos responsáveis pela resposta a "O que?" (O que é isso?), encontram-se na parte anterior do cérebro, especificamente, na área temporo-frontal. Eles são acessados mais facilmente, são de uso constante, e guardam as informações mais "genéricas", válidas para todos os sujeitos de uma determinada cultura. As respostas: É uma fruta, ou É uma maçã, pertencem a este processo. ${ }^{8}$ Ainda segundo Damásio (2011, p. 176 e ss.) os circuitos que respondem a "Onde?", ao contrário da generalidade e imediatice do "O que ?" requerem outra complexidade. Esses circuitos se movem para a parte posterior

\footnotetext{
Por exemplo, no Brasil dos anos $70 / 80$ a palavra "bicho" significava "amigo e não apenas um espécime da fauna."

Em culturas diferentes a resposta para esta pergunta é variável em função da língua falada, mas é invariável em relação ao significado e designação. Ser uma fruta, ou um animal é uma categoria válida em todas as línguas e culturas.
}

$$
=76=
$$


e mais interna do cérebro, áreas parieto-ocipital, e ali vão buscar dados da experiência e do conhecimento particular de cada sujeito. ${ }^{9}$ A resposta para "Onde?" requer a evocação de fatos e contextos que pertencem necessariamente a história de vida do sujeito respondedor. Por isso, Damásio escolheu denominá-la "Única" em oposição à memória "Não única", ou genérica, do processo anterior.

Esse autor usa como exemplo a palavra casa para indicar as diferenças, mas também os imbricamentos, entre esses dois processos mnemônicos. Confrontado com a palavra casa o sujeito pode evocar o sentido social mais genérico como "lugar onde as famílias habitam". Neste caso, estaria usando um recurso da memória genérica ou "Não Única". Mas, especialmente se junto a esta palavra surgir uma imagem visual da casa que ele habitou durante a infância, ou outro tipo de imagem (sonora ou olfativa, por exemplo), a rememoração e o sentido poderão ganhar outra complexidade e particularidade. ${ }^{10}$ Neste caso, a memória mais particular ou "Única" estaria participando ativamente do processo de significação.

Quando define a memória Única como mais particular e de grande complexidade, e a memória Não Única como genérica e de menor complexidade, Damásio não descarta a atuação dos dois tipos em um mesmo processo de evocação. Neste caso, vislumbra um tipo de hierarquia, entre a menor e maior complexidade, na qual os processos mistos poderiam apresentar uma média complexidade (idem, p.177) .

Se a memória é um conjunto de processos de armazenamento de dados, a aprendizagem, para além deste armazenamento, mostra a sua eficácia quando o sujeito é capaz de combinar dados de sua memória para inferir novas descobertas.

A memória e a aprendizagem dependem da formação de uma ligação (sinapses) entre as células cerebrais principais, os neurônios. Nossas modalidades perceptivas sensoriais são, digamos assim, a porta de entrada para os dados que ficam impressos nos conjuntos de neurônios que compõem a nossa memória. De algum modo o nosso corpo, exposto a infinitos estímulos externos (ruídos, imagens visuais, vozes, cheiros,...), seleciona e foca a sua

\footnotetext{
${ }^{9}$ Para Damásio (idem, p.176) é essa memoria única, particular a cada sujeito, que atua cada vez mais e progressivamente na sua vida, configura o que nós denominamos "mente". Assim, a "mente" é diferente, e ainda muito mais complexa do que denominamos "cérebro".

${ }^{10}$ Para os vários tipos de imagem cerebral ver Damásio (2000) ou Duarte(2011).
}

$$
=77=
$$


atenção em um determinado conjunto de percepções que serão registradas como um novo dado, uma nova memória. ${ }^{11}$ Armando Rocha define aprendizagem e memória como "... fenômenos que envolvem transações entre neurônios em sistemas neurais amplamente distribuídos no cérebro." (ROCHA, 1999, p.126) e conclui: "Cada área cerebral tem uma participação definida no processo, mas nenhuma delas é sede desses processos. A participação de cada área nesses processos está relacionada com a sua especialização." (Idem, ibidem) No conjunto altamente complexo das subdivisões e especializações das áreas cerebrais, importa aqui recordar, que as modalidades perceptivas sensoriais que acabamos de identificar como "a porta de entrada" de todos o tipos de informação com os quais o nosso cérebro trabalha, respondem, no conjunto de tecido neuronal, a zonas ou áreas específicas. Se ao longo da história da medicina e da neurologia, os danos cerebrais em diferente vítimas humanas ajudaram a mapear essas áreas específicas, atualmente, os recurso de neuroimagem permitem precisá-las. ${ }^{12}$

\section{Desenvolvimento, aprendizagem, memória, cognição e desenho}

Quando a partir dos três meses de idade a criança começa a fase do balbucio, precedente à vocalização das primeiras palavras, ela já demonstra uma grande excitação quando consegue articular um som novo, a mesma excitação que evidencia quando seu cuidador, em meio a brincadeiras de fonação, apresenta-lhe uma nova sílaba troncando, por exemplo, a verbalização de da, da, da por mu,mu,mu. Este fato torna manifesto os rudimentos de uma capacidade fundamental do cérebro humano: a capacidade de identificar similaridades e disparidades. Esta capacidade é essencial para toda a aprendizagem que virá, uma vez que serão necessárias as categorizações que viabilizam, do ponto de vista semântico (memória explícita ou não única) o funcionamento cerebral. Tratase de agrupar objetos semelhantes e por meio desse agrupamento inicial ser capaz de reconhecer, em um objeto novo, certo grau de assemelhamento e pertencimento que o torna mais facilmente

\footnotetext{
11 Em "Psychologie de l' enfant" de 2004, Houdé chama atenção para a importância dos " inibidores cerebrais", um processo que provoca a atenção seletiva e sem o qual nosso cérebro ficaria assoberbado frente a um número infindável de estímulos sensoriais.

12 Para as diferentes modalidades perceptivas e suas áreas especializadas no cérebro ver, por exemplo, Rocha (1999) e/ou Lent (2005).
}

${ }^{13}$ Ver para isso, por exemplo, NEWCOMBE, 1999, p. 212 e ss.

$$
=78=
$$

ISSN: 2447-1267 Santa Catarina, v.5, n.1, ano 3, março de 2017. 
identificável e assimilável. (Sem essa capacidade, na primeira vez que nos deparássemos com um urso, poderíamos perder a vida, tentando decifrar aquela coisa totalmente desconhecida.)

Há dúvidas se os bebês, antes de um ano de idade, agrupam os objetos do mundo por meio de relações temáticas ou taxonômicas. As relações temáticas permitem associações entre coisas que não pertencem a uma mesma categoria mas, por exemplo, podem pertencer a um mesmo cenário. Assim, é possível reunir macaco/banana ou gato/sofá. ${ }^{14}$ Já um conjunto taxonômico reuniria, por exemplo, macaco/gato, classificados como animais e pertencentes a uma grande categoria natural.

Mas, Newcombe (1999) assevera que, mesmo frente a explosão de novas aquisições que se sobrepõem nos primeiros meses de vida, "... até o final do primeiro ano, as crianças tem um entendimento inicial firme sobre a estrutura categorial do mundo" (p.147). Isto é, as crianças já possuem mesmo na mais tenra idade, uma tendência para agrupar os objetos de modo taxonômico, de acordo com o seu pertencimento ou não a categorias naturais (os animais gato e macaco do nosso exemplo). Newcombe ressalta, ainda, que a linguagem (sua aquisição pela criança) tem, entre outras, a importante função de ajudar na demarcação de categorias perceptuais e conceituais por meio da representação simbólica oferecida pelas palavras e anota que este fato está altamente relacionado com a possiblidade de "inferir e deduzir", habilidades essas que "compreendem a essência da racionalidade humana" (Idem, p.212).

No "Vocabulário Pictográfico para educação inclusiva" (DUARTE e PIEKAS, 2013) Mari Piekas e eu enfatizamos, de acordo com a proposta de Eleanor Rosch, os elementos pertencentes ao Nível Cognitivo de Base (palavras e desenhos, no nosso caso), como aqueles a serem privilegiados na etapa escolar inicial. Em suas pesquisas Rosch pode comprovar a universalidade e o caráter prototípico dos elementos pertencentes a este nível de cognição assim como o "ar familiar" que permanece agregado a esses termos (Rosch, 1978). Nora Newcombe, contemporânea de Rosch na Universidade de Harvard nos Estados Unidos, ao atualizar a

\footnotetext{
${ }^{14}$ Em pesquisas preliminares com crianças cegas, encontrei algumas com mais de 7 anos de idade que agrupavam os objetos segundo esse critério cenográfico. (DUARTE, dados ainda não publicados.)
} 
abordagem cognitiva de Mussen para o desenvolvimento infantil (NEWCOMBE, 1999), agrega ou reitera a importância do Nível Cognitivo de Base, ainda que não cite literalmente Rosch. ${ }^{15}$ Mas, é importante sublinhar o lugar do qual Newcombe revê e privilegia este nível cognitivo: a partir de pesquisas com bebês e crianças pequenas nas quais a aprendizagem da fala e a formação de conceitos são acompanhadas e testadas.

No âmbito da modalidade perceptiva visual, que é essencial para o ato de desenhar assim como a modalidade motora, requer salientar que: a) objetos em movimento são aqueles que mais atraem - olhar atento das crianças e que esta atenção é perceptível muito cedo porque o pesquisador/observador precisa apenas registrar o movimento ocular da criança; b) pessoas, animais domésticos e veículos são os primeiros objetos, e as primeiras categorias, que se movimentam perto das crianças; c) frente ao movimento, ao olhar atento e a percepção deste interesse, pais e cuidadores tendem a nomear para as crianças esses objetos. Desta tríade, objeto em movimento/olhar atento/nome do objeto, surge as primeiras relações entre figuras (o objeto em sua totalidade) e o seu nome. Duas premissas são fundamentais aqui: i) é o movimento que estabelece para a criança a relação correta entre a totalidade do objeto e o seu nome; ii) é a percepção da totalidade do objeto (asseverada pelo movimento) e o conjunto de detalhes de sua forma visual que, mais tarde, vão permitir que a criança estabeleça relações de pertencimento categorial entre, por exemplo, o gato e o cão. São as figuras visuais compostas e completas do gato e do cão (com corpo, cabeça, quatro patas, orelhas e rabol, associadas a contextos espaciais específicos, que irão permitir o processamento mental de semelhanças e discrepâncias entre dois objetos (o cão e o gato) e a dedução de pertencimento a um mesmo grupo categorial. Na avaliação mental nada impede a compressão de que o cão é um pouco diferente do gato, mas imprime-se com maior força a constatação de que o cão e gato são extremamente diferentes de "papai "ou "sofá". Neste caso a configuração "ter cabeça, corpo, quatro patas e rabo é a dica visual para agrupar cão e gato na mesma categoria geral e natural.

o "girino" é a primeira figura desenhada pelas crianças logo após a fase de garatujas e é a única configuração que sabemos ser

${ }^{5}$ NEWCOMBE, 1999, ver para isso especialmente p.220. 


\section{APOTHEKE}

ESTÚDIO DE

P I N T URA

interferência de outra pessoa. Considero que o desenho do girino espelha com perfeição a associação entre totalidade, ou inteireza formal do objeto visual, e o seu movimento (ver Fig. 1), pois neste precedente das demais representações gráficas (o desenho do girino), o corpo humano é apresentado por meio de uma única forma circular. Rompendo com essa unicidade formal, a criança completa o seu desenho acrescentando filamentos à forma circular. ${ }^{16}$ Estes filamentos registram exatamente o segundo termo do binômio totalidade/movimento, isto é, apresentam os membros (pernas e/ou braços) que conferem aos humanos a possibilidade de deslocamento no espaço.
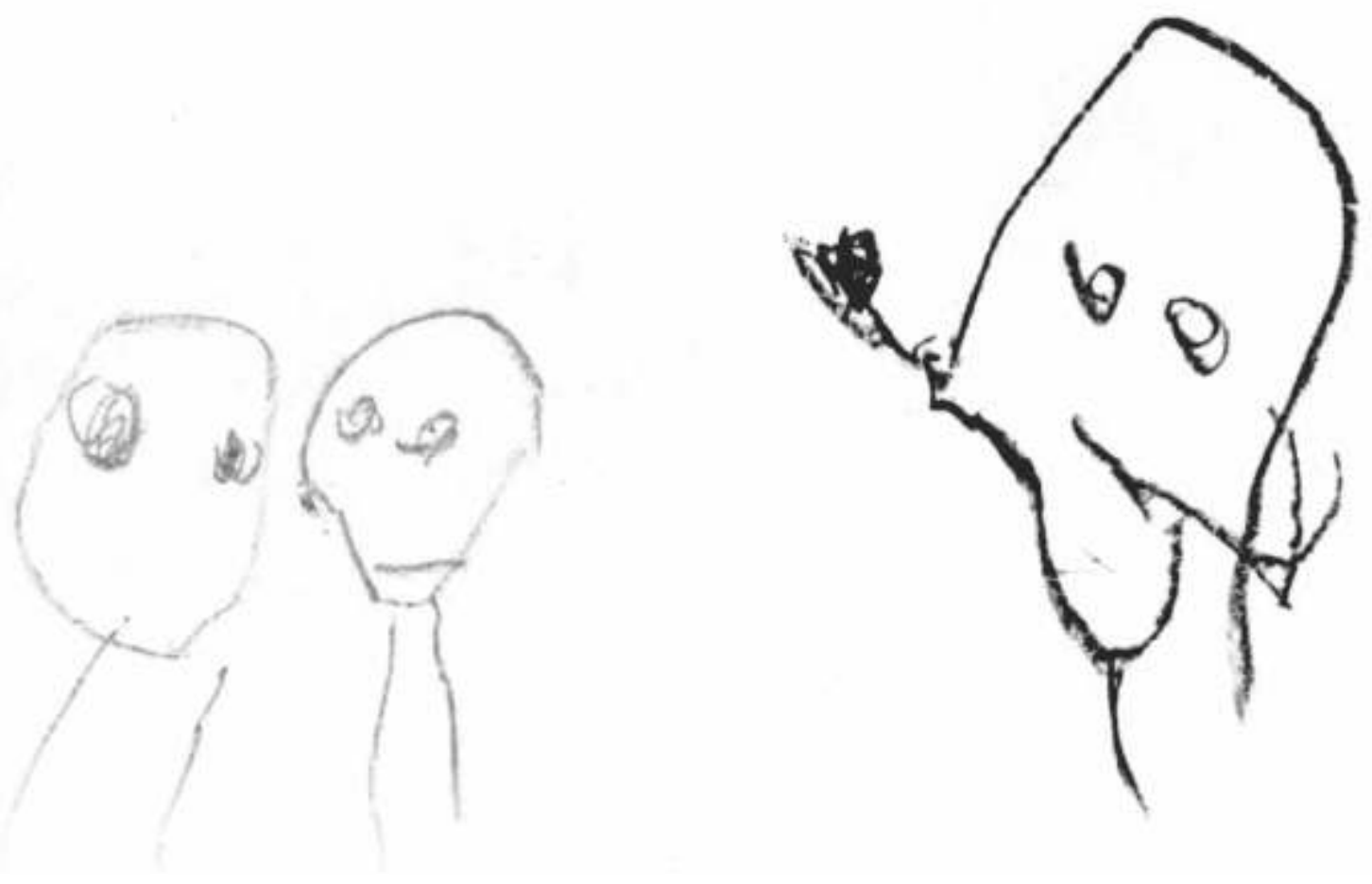

Fig. 1. Girinos. Desenho de Lucas, 3a6m. Fonte: LabDIA

16 Luquet foi pioneiro em estudo sobre a configuração do girino em cuja forma circular percebe ora a representação apenas da cabeça, ora a representação do corpo em sua totalidade, isto é, incluindo o torso (LUQUET, 1910). A relevância deste estudo foi reconhecida mais de cinquenta anos depois pelo teórico da arte Rudolf Arnheim (ARNHEIM, $1980)$.

$=81=$ 
Este registro do visual, por meio da totalidade da forma e do movimento, encontra respaldo, também, no fato de a criança, na primeira infância, ter ainda o seu sistema visual cerebral em formação e adaptação. O aparelho perceptivo visual permitirá uma visão plena e detalhada dos objetos apenas em torno dos 5 anos de idade (Newcombe, 1999; Hatwell, 2003).

\title{
3. O ato de desenhar e o nível de base
}

O ato de produzir linhas e formas gráficas sobre uma superfície plana adquire a caracterização plena de "desenho" depois da experiência gráfico-motora das garatujas (iniciada após os 2 anos de idade), e das primeiras representações de girinos, cuja configuração inaugura e atesta a presença da visualidade como um claro e eficiente recurso de aprendizagem.

Lowenfeld e Brittain classificam os primeiros desenhos infantis ou girinos como pré-esquemas (LOWENFELD e BRITTAIN, 1977). Estes pré-esquemas resultam, em sequencia, em uma primeira série de esquemas gráficos entre os quais a representação da figura humana é altamente exercitada. Luquet (1927) estabeleceu uma relação precisa entre esses esquemas, que ele denominou "tipos gráficos" e um registro mental, ou memória, que denominou "modelo interno".

O aspecto que marca a evolução do pré-esquema para o esquema é a presença da definição gráfica das partes que compõem o todo visual das figuras. Isto é, aquela totalidade em movimento registrada no girino cede paulatinamente espaço ao desenho de um objeto registrado com maior acuidade visual e detalhamento, no qual o movimento dá lugar a certa rigidez que se torna necessária e cúmplice à suspensão do tempo requerida pelo ato de desenhar.

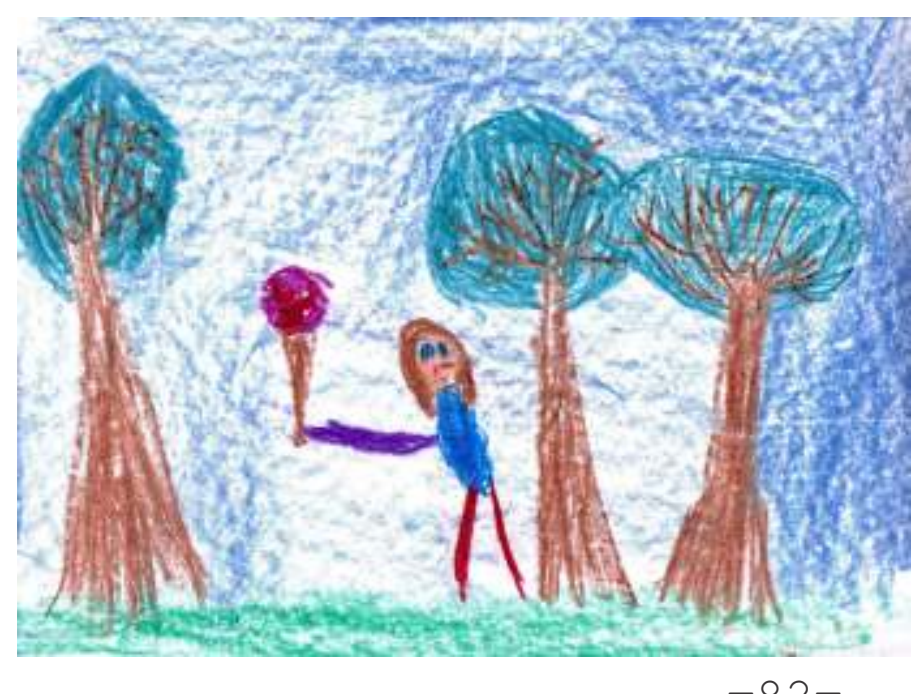

\author{
Fig. 2. Esquema 1 \\ Desenho de Sebastian, \\ 7 anos.
}

Fonte: LabDIA

ISSN: 2447-1267 Santa Catarina, v.5, n.1, ano 3, março de 2017. 


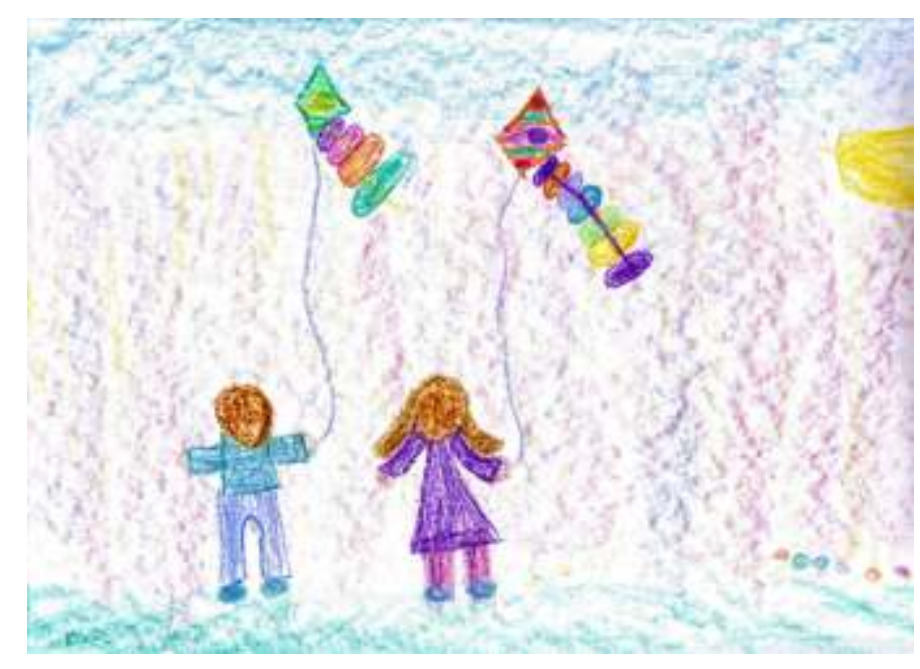

Fig. 3. Esquema 2

Desenho de Maria Antonia, 7a 5m Fonte: LabDIA

Observando a Figura 2, pode-se verificar que a evolução do préesquema (do "girino") faz surgir na representação da figura humana um corpo ou torso, distinguindo-o da cabeça, ainda que a representação permaneça de certo modo assexuada e apenas alguns detalhes, como o cabelo ou acessórios, lhe confiram certa identidade. Já na Figura 3 a grande categoria "ser humano" recebe, do ponto de vista formal e gráfico, uma subdivisão por gênero fazendo a distinção entre menino e menina.

Mas, finalmente, qual a relação entre o desenhar e a aprendizagem como um todo?

Compreendo que o ato de desenhar e o desenho são recursos altamente produtivos durante a aprendizagem (e memorização) das categorias que organizam e classificam os objetos do mundo e que, esta categorização é fundamental, basilar, nos demais processos de aprendizagem.

A capacidade humana para identificar semelhanças, discrepâncias e deduzir generalizações, estabelecer classificações, parece, definitivamente, ser o processo que sustenta a memória semântica (ou Não Única) a qual permite, a nós humanos, além dos processos cognitivos, a comunicação e sociabilidade que nos caracterizam.

Eleanor Rosch (ROSCH, 1973, 1975) denominou "nível de base" este lugar cognitivo e mental no qual os objetos do mundo encontram uma primeira grande organização e classificação. Linguista, ela se ateve às palavras para indicar este nível e nomeou diferenciando: cadeira, lâmpada, pássaro,... Mas, onde não havia palavras, como na comunidade dos Dani em Papua Nova Guiné esta pesquisadora utilizou 
figuras, imagens visuais, que, igualmente, lhe permitiram identificar os objetos do nível de base ou prototípicos. ${ }^{17}$

No "Vocabulário pictográfico para educação inclusiva" (DUARTE e PIEKAS, 2013), Mari e eu oferecemos as crianças com necessidades educacionais especiais uma possibilidade gráfica e visual de aprender a identificar alguns animais do nível cognitivo de base. Isto porque temos razões teóricas para crer que a construção e desconstrução visual e gráfica de animais típicos, e pertencentes a esta classificação de base, podem constituir um importante recurso nos processos de aprendizagem. ${ }^{18}$

Nós estabelecemos uma relação estreita entre dizer/escrever o nome do objeto e desenhar a sua figura. Do ponto de vista da constituição de uma aprendizagem e de uma memória semântica, o entrelaçamento entre diferentes aspectos perceptivos (forma visual do objeto/nome do objeto falado ou escritol propicia a reunião de recursos mentais oriundos de diferentes modalidades perceptivas que reiteram e fortificam esta aprendizagem. A presença do esquema gráfico (do Pictograma) junto à palavra que o nomeia torna a palavra concreta e refaz a experiência infantil na qual, com o auxilio de pais, cuidadores e professores, a criança vai olhando, tocando, cheirando, os objetos do mundo e descobrindo os seus nomes.

Para a produção do "Vocabulário Pictográfico para educação inclusiva - 1 Animais", além do grande arquivo digital com desenhos infantis que já nos orientava ${ }^{19}$, foi realizada nova coleta de desenhos com a finalidade de ampliar os dados já obtidos e, posteriormente, uma seleção criteriosa na qual buscamos relacionar aspectos como repetição, simplicidade, objetividade e clareza informacional. Como na fatura dos pictogramas informacionais utilizados como linguagem visual universal (códigos de trânsito, indicadores em aeroportos de entrega de bagagem e toaletes, por exemplo) e respeitando o modo como a própria criança constrói os seus esquemas gráficos, os pictogramas do "Vocabulário" foram desenhados com as linhas e formas geométricas mais simples, primordiais e acessíveis.

\footnotetext{
${ }^{17}$ Ver para isso DUARTE e PIEKAS, 2013 ou DUARTE, 2011.

${ }^{18}$ Temos comprovado isto em nosso trabalho e pesquisa com crianças cegas.

9 Arquivos do LabDIA (Laboratório de pesquisa em Desenho Infantil e Adolescente.
} $=84=$ 


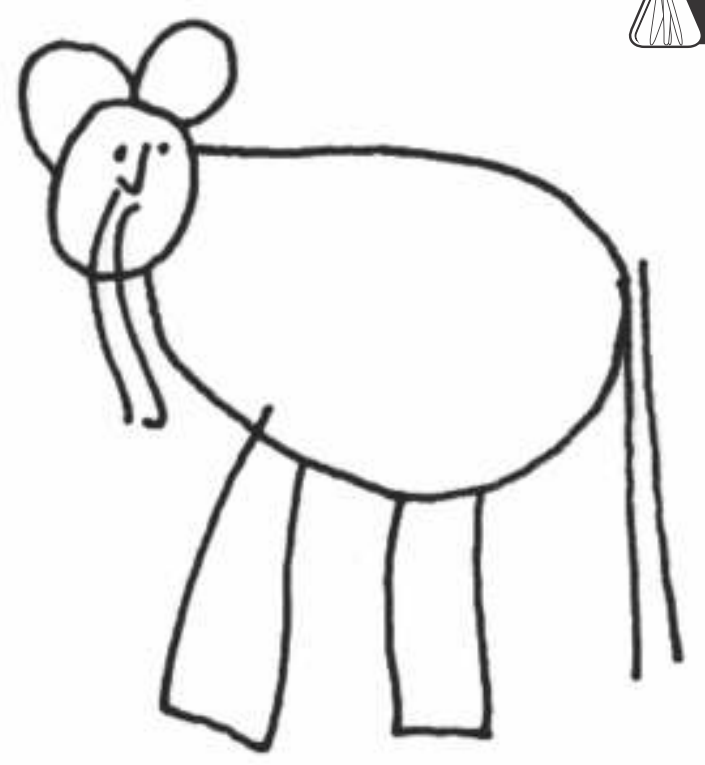

Fig. 4. Desenho de Vitória, 8 anos.

Fonte: LabDIA

Fig. 5. Pictograma criado por Mari Piekas. (DUARTE E PIEKAS, 2013)
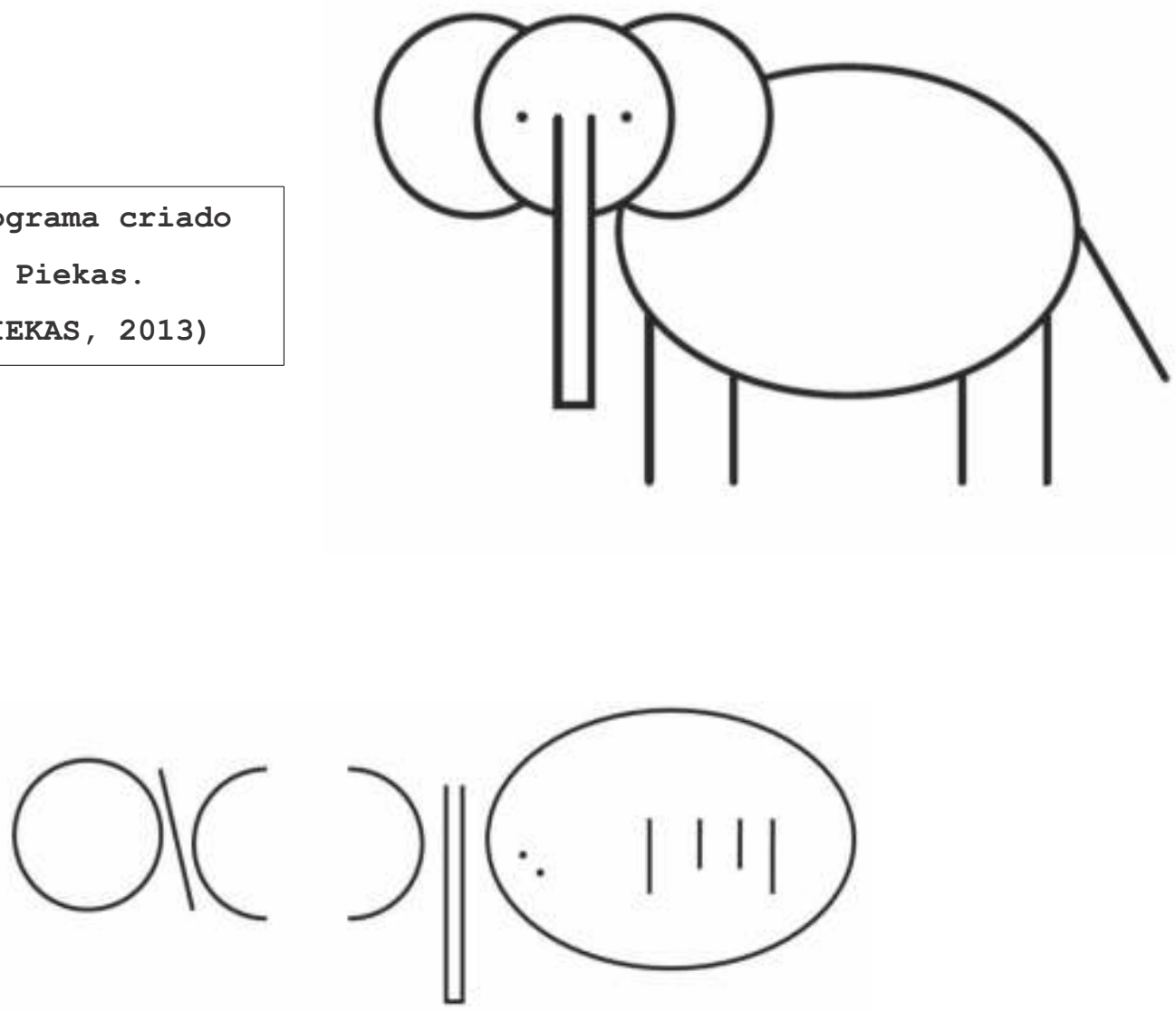

Fig. 6. Figuras geométricas, linhas e pontos que configuram - Pictograma do Elefante. (DUARTE e PIEKAS, 2013)

\section{$=85=$}


A Figura 4 é um exemplo de desenho infantil (esquema gráfico) que deu origem a um pictograma. Neste caso, trata-se do pictograma "elefante" conforme está apresentado na Figura 5. Ele é oferecido aos pais e professores de crianças com necessidades educacionais especiais como modelo gráfico deste animal, como um protótipo que representa uma categoria do nível cognitivo de base. No livro esclarecemos, também, que os elefantes pertencem a grande categoria do nível cognitivo superordenado (abstrato) denominada "animais mamíferos".

Na Figura 6, o mesmo elefante do pictograma (Fig. 5) está desconstruído nas linhas, pontos e figuras geométricas utilizadas para desenhá-lo. No livro, nós propomos que as crianças exercitem a grafia de linhas e figuras antes de se dedicarem a reprodução e aprendizagem dos pictogramas.

Com a proposição dos pictogramas pretendemos que as crianças possam otimizar o processo de aprendizagem estabelecendo fortes conexões entre: o ato motor de produzir o desenho; a visualidade e/ou tatilidade do objeto sendo desenhado e finalmente desenhado em sua totalidade; a sonoridade e/ou a visualidade da grafia do nome do objeto. Isto é, exercitem recursos perceptivos mais amplos para efetuar a memorização e a aquisição de um novo conhecimento.

\section{Reflexões Finais}

De modo muito simples e sintético tento resumir, no elemento gráfico apresentado a seguir, aspectos da abordagem de aprendizagem construída neste texto e suas vinculações com o ensino de desenho para estudantes com necessidades educacionais especiais. Estabeleço relações de interdependência entre: o sujeito e seus "canais receptores" ou modalidades sensoriais; as sociedades e seus processos generalizadores e categoriais; os objetos do mundo e seus sinais de presentificação (formas, sons, cheiros, gostos); e a própria aprendizagem, cuja efetivação requer um movimento orgânico e continuo entre estas "partes".

Percebo a educação inclusiva como uma ação que visa minimizar as "faltas" ou deficiências a partir de estratégias de compensação e provocação cuja finalidade é, de um lado, acreditar nas potencialidades de todos os alunos, e de outro lado, criar possibilidades para que as diferenças, bem aceitas, sejam reconhecidas e enfrentadas proporcionando a aproximação e o assemelhamento que parece deixar mais felizes aqueles que sentem qualquer tipo de privação.

$$
=86=
$$




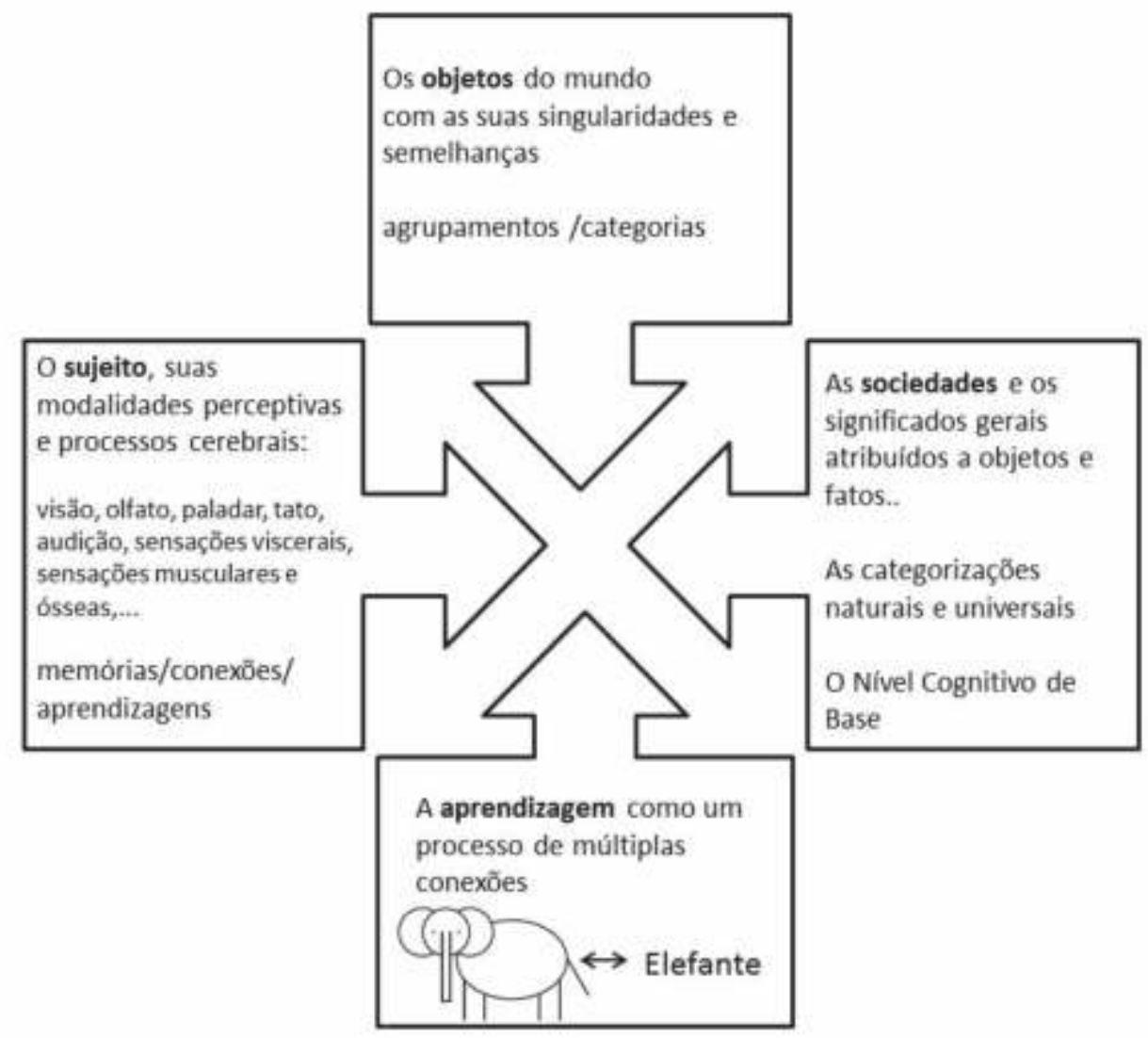

Gráfico 1. Síntese. Fonte: concepção desta autora

Percorrer os processos de aprendizagem com a abordagem neurocientífica e cognitiva permite compreender como o nosso corpo aprende em toda a sua dimensão e complexidade, entre o mais simples movimento de pinçar o lápis de desenho e o mais sofisticado processo de movimento ocular. Trata-se de, com o corpo e com a mente realizar, por exemplo, uma distinção visual entre formas e cores, ou entrelaçar diferentes modalidades perceptivas que ao final podem produzir um novo sentido, oferecer uma nova significação para cada objeto ou cada fato com os quais nos deparamos durante a vida. Talvez educar seja simplesmente um ato que visa facilitar esses encontros, essas significações e ressignificações.

Mas, pinçar, pedalar, desenhar, provar uma fruta, conhecer um animal, escrever, ler, resolver um problema matemático... nenhuma ação, nenhum evento novo, nenhuma experiência possibilitada simplesmente pelos nossos sistemas sensoriais, pelo nosso meio ambiente cultural, ou por um ensinamento, seria transformada em aprendizagem se o nosso cérebro não realizasse uma estocagem chamada memória.

$$
=87=
$$




\section{Referências}

ARNHEIM, Rudolf. Arte e percepção visual. (nova versão) São Paulo: Pioneira EDUSP, 1980 .

BIDEAUD, Jacqueline. HOUDÉ, Olivier, PEDINIELLI, Jean-Louis. I’homme en développement. Paris: PUF, 2004.

COX, Maureen. Desenho da criança. São Paulo: Martins Fontes, 2000. Tradução: Evandro Ferreira.

DAMÁSIO, Antonio. o mistério da consciência. São Paulo: Companhia das Letras, 2000. Trad: Laura Teixeira Motta.

DAMÁSIO, Antonio. Como o cérebro cria a mente. Scientific American. Ed Especial: Os segredos da mente, n.4, 2004, p.6-11.

DAMÁSIO, Antonio. E o cérebro criou o homem. São Paulo: Companhia da Letras. 2011.

DARRAS, Bernard. " $L$ ' image un vue de $I$ ' esprit. Étude comparée de la pensée figurative et de la pensée visuelle. Recherches em communication, n.9, Bélgica, 1998 .

DOIDGE, Norman. O cérebro que se transforma. Como a neurociência pode curar as pessoas. Rio de Janeiro : Record, 2011.

DUARTE, Maria Lúcia Batezat. Pedras e água: um estudo sobre desenho e cognição. In: XI Encontro Nacional da ANPAP, 2001, São Paulo. Anais do XI Encontro da Associação Nacional dos Pesquisadores em Artes Plásticas, CD-R, São Paulo: ANPAP, 2001.

DUARTE, Maria Lúcia Batezat "Sobre o funcionamento cerebral e a importância do desenho para os cegos". In: MEDEIROS, Maria Beatriz (org) A arte pesquisa I. Ensino e aprendizagem da arte e linguagens visuais. Brasília, DF: UnB, V1, 2003, p. $113-127$.

DUARTE, Maria Lúcia Batezat. "Imagens mentais e esquemas gráficos: ensinando desenho a uma criança cega." In: MEDEIROS, Maria Beatriz (org) Arte em pesquisa: especificidades. Ensino e aprendizagem da arte e linguagens visuais. Brasília, $\mathrm{DF}$ : UnB, V2, 2004, p.134-140.

DUARTE, Maria Lúcia Batezat. Representação, categoria cognitiva e desenho infantil. In: ROCHA, Cleomar (org) Anais do $15^{\circ}$ encontro Nacional da ANPAP Arte: limites e contaminações. Salvador: ANPAP, 2007, p.468-481.

DUARTE, Maria Lúcia Batezat. A imitação sensório-motora como uma possibilidade de aprendizagem do desenho por crianças cegas. Revista Ciências \& Cognição; vol.13 (2) 14-26, 2008. www.cienciasecognicao.org. (2008a)

DUARTE, Maria Lúcia Batezat. Dibujo infantil y cognición: un estudio sobre las propiedades formales de los objetos y la elaboración de las categorías cognitivas in: RUIZ, Antonio. et al (coord) Protótipos, Lenguaje y representación en las personas ciegas. Cádiz, ES. Servicio de Publicaciones de la Universidad de Cádiz, 2008.pp. 97-122.(2008b)

DUARTE, Maria Lúcia Batezat. Desenho infantil e seu ensino a crianças cegas. Razões e método. Curitiba: Insight, 2011.

DUARTE, Maria Lúcia Batezat e PIEKAS, Mari Ines. Vocabulário pictográfico para educação inclusiva. 1 Animais. Curitiba: Insight, 2013. 
GUÉRIN, Fanny. SKA, Bernardette. BELLEVILLE, Sylvie. "Cognitive processing of drawing abilities." Brain and Cognition, n. 40, p. 464-478, 1999.

HATWELL, Yvette. Psychologie cognitive de la cécité précoce. Paris : Dunond, 2003 .

HOUDÉ, Olivier. MAZOYER, Bernard. MAZOYER, Nathalie Tzourio-. Cerveau et psychologie. Introduction à l'imagerie cérébrale anatomique et fonctionnelle. Paris: PUF, 2002 .

HOUDÉ, Olivier. La psychologie de l'enfant. Paris: PUF, 2005.

JEANNEROD, Marc. "Système nerveux et aprrendissage" Apprendre \& Eduquer. Les cahiers millénaires.n.31, Lyon, France, 2005. pp. 21-27.

JEANNEROD, Marc. " La main, l'action et la conscience " entrevista in: DORTIER, Jean-François. (coord) Le cerveau et la pensée. Paris: Editions Sciences Humaines, 2003.pp.441-449.

LENT, Roberto. Cem bilhões de neurônios: Conceitos fundamentais de neurociência. São Paulo: Atheneu, 2005.

LIMA, Francisco José de. O efeito do treino com desenhos em relevo no reconhecimento háptico de figures bidimensionais tangíveis. Tese de doutoramento. FFCL, USP Ribeirão Preto, SP, 147 p, 2001.

LOWENEELD, Vicktor e BRITTAIN, W.L. Desenvolvimento da capacidade criadora. São Paulo: Mestre Jou. (1947) 1977. Trad. Álvaro Cabral.

LUQUET, Georges-Henri. "Sur les debuts du dessin enfantin" Texto apresentado no "Congrès International d'education familiale", 1910, impresso, Biblioteca Nacional da França, BNF.

LUQUET, Georges-Henri. O desenho infantil. Porto: Ed. Minho, (1927) 1969. Trad: Maria Teresa Gonçalves de Azevedo.

NEWCOMBE, Nora. Desenvolvimento infantil. Abordagem de Mussen. Porto Alegre : Artmed, 1999.

NICOLELIS, Miguel. Muito além do nosso eu : a nova neurociência que une cérebros e máquinas - e como ela pode mudar nossas vidas. São Paulo: Companhia das Letras, 2011 .

OLIVERIO, Alberto. Cerebro. Buenos Aires: Adriana Hidalgo Editora, 2013. Trad. Ines Marini y Rodrigo Molina.

PIEKAS, Mari Ines. A desconstrução do esquema gráfico aplicado ao ensino de desenho para crianças cegas. Dissertação de Mestrado. Florianópolis, PPGAV/UDESC, 2010

PILLAR, Analice Dutra. Desenho e escrita como sistemas de representação. Porto Alegre: Penso, 2012. $2^{a}$ ed. ampliada.

ROCHA, Armando Freitas da. O cérebro. Um breve relato de sua função. Jundiaí, SP: CMYK, Design, 1999.

ROSCH, Eleanor. Natural categories. Cognitive Psychology. n.4, 1973, p.328-350.

ROSCH, Eleanor. Cognitive representation of semantic categories. Journal of experimental psychology: General, n.104, 1975, p. 192-233.

ROSCH, Eleanor. Principles of categorization. In: ROSCH, E., LLOYD, B. (eds.) $=89=$ 


\section{APOTHEKE}

ESTÚDIO DE

P I N T URA

Categorization and cognition. N.J.: Hillsdale, 1978, p.27-47.

TROADEC, Bertrand. Le développement de la pensée chez l'enfant. Catégorisation et cultures. Toulouse : Press Universitaire du Mirail, 1999.

WINNYKAMEN, Fayda. Apprendre en imitant? Paris:PUF, 1990.

\section{Maria Lúcia Batezat Duarte}

Possui graduação (licenciatura) em Artes Plásticas pela Universidade Federal do Rio Grande do Sul (1980), mestrado em Ciências da Comunicação pela Universidade de São Paulo (1989), doutorado em Artes pela Universidade de São Paulo (1995) e pós-doutorado na Université Paris-1, Sorbonne (2006). Em 2011 publicou o livro DESENHO INFANTIL E SEU ENSINO A CRIANÇAS CEGAS. RAZÕES E MÉTODO, com apoio da CAPES, onde apresenta toda a sua experiência e estudos na área do desenho infantil e da invisualidade. A importância do desenhar na infância é abordada, no livro, a partir de princípios oferecidos pelas Artes Visuais, a Psicologia Cognitiva e a Neurociência. Em 2013, publicou com Mari Ines Piekas o livro VOCABULÁRIO PICTOGRÁFICO PARA EDUCAÇÃO INCLUSIVA. 1 ANIMAIS no qual buscam estender a possibilidade de desenhar e identificar figuras gráficas do Nível Cognitivo de Base para todas as crianças com necessidades educacionais especiais. Este livro está disponibilizado gratuitamente, também em versão em inglês, no site da Editora Insight.

http://lattes.cnpq.br/2670000362289218 